\title{
The Connotation and Strategy of College Students' Leadership Training Lei $\mathrm{Yu}^{1, \mathrm{a}^{*}}$, Yuan $\operatorname{Tian}^{1, \mathrm{~b}}$ and Fengjiao $\mathrm{Xu}^{3, \mathrm{c}}$ \\ ${ }^{1}$ No. 188, The Second Road, Zhifu District, Yantai City, Shandong, China \\ ${ }^{3}$ NO.5, Xinxing North Road, Laishan District, Yantai City, Shandong, China \\ a*yulei0389@sina.com, btiayuan@163.com, ㄷytzjsxfj@163.com
}

\section{Keywords: College Student; Leadership; Training; Connotation; Strategy}

\begin{abstract}
Colleges and universities have the important responsibility of cultivating all kinds of high quality talents and leaders for the society. At present, many colleges and universities are exploring the different mode and way of Cultivating College Students' leadership. We find that the Students' leadership training still exist many problems based on the literature research, questionnaire survey; Combined with the teaching practice, the connotation of leadership research, the orientation of training ideas, we need to improve the training system, optimize the training process and the construction of evaluation system, and promote the improvement of College Students' leadership.
\end{abstract}

\section{Introduction}

The cultivation of College Students' leadership is designed to cultivate the leadership ability of college Students', which involves many subjects, such as leadership science, management science, organizational behavior, sociology, politics, pedagogy, psychology and so on. With the constantly updated concept of talents and higher education reform, the cultivation of talents with excellent leadership has become an important task for colleges and universities, the "national long-term education reform and development plan (2010-2020)" clearly pointed out that China should focus on training Students' to become a excellent leader. ${ }^{[1]}$ Therefore, it is an important content for higher education to pay attention to the cultivation of College Students' leadership.

\section{The Research of Current Situation of Leadership}

Leadership is a new topic in the field of Leadership Science in recent years. American scholars have always been in a leading position in the study of leadership, and extend it to the field of College Students' education on the basis of relatively mature leadership theory. In early 1970s, Susan R. Komives and others who worked at the University of Tennessee, Bbenison University have studyed leadership, extracurricular activities and projects, and opened a special leadership course at Denison university. ${ }^{[2]}$

With the research and teaching practice, American College Students' Leadership Education became increasingly specialized, the leadership education has theoretical framework, established a system of the concept model, practice standard and diverse teaching methods. In this area, there are a large number of Students' centered and reflect the diversity of Students' development scholarship evaluation, crisis assessment, and leadership education support system such as professional associations and graduate preparation courses. ${ }^{[3]}$

With the college leadership training development in western countries represented by the United States, domestic scholars increasingly take aware of the enormous role of leadership development for college Students' personal development and social progress, the research and development of the leadership of college Students' gradually aroused the attention of domestic scholars in recent years, many personas take more and more attention to college Students' leadership. At present, the research on College Students' leadership in China is mainly about the comparative study on the leadership education of college Students' in foreign countries, and the investigation and report on the development of College Students' leadership quality. But there are just few colleges and 
universities carry out the cultivation of College Students' leadership, most college have not received enough attention to the importance of College Students' leadership training.

\section{The Connotation of College Students' Leadership}

Leadership theory originated between the late nineteenth Century and early twentieth Century, many scholars focus on the leader's personality traits in the beginning, it has undergone four main stages, it is the trait theory, style theory, contingency theory and situational/transformational leadership theory. Many researchers at home and abroad define leadership from different angles. James and Barry, in the book "leadership", define "leadership is the art of motivating people to work together for the common vision of the world" in the book of the <<leadership >>. ${ }^{4]}$ Bennis believes that leadership is the ability to turn vision into reality. Chapman and O.neil believe that leadership is the ability to influence others and inspire others to achieve challenging goals. ${ }^{[5]}$

Our country scholar $\mathrm{Xi}$ Jieren believed that leadership is essentially a kind of influence, especially the ability to guide people towards the right direction or organization and influence people the ability to achieve a goal. ${ }^{[6]}$ Zhu Dexin believes that leadership is based on leadership, leadership system, leadership quality, leader lead and management subordinates and stakeholders, to achieve common goals and aspirations of a kind of ability and influence. ${ }^{[7]}$

From the different experts and scholars interpretations of leadership, we can find that leadership is a kind of ability, this ability is a person who can apply "influence" to the organization or others, and this ability has some purpose, it is not only exist in a person, also exist in ordinary people in the a organization. Leadership training is mainly aimed at training the ability of leadership in some leadership activities, promote the development of leadership research and practice in the school system, community and enterprise and government and other organizations. ${ }^{[8]}$ the training methods should be divided into general education, practical teaching project team mentoring and community interaction. ${ }^{[9]}$ according to the theory of leadership and the law of education colleges should have a purposeful, planned and organized influence for all college Students', so that it has leadership practice. ${ }^{[10]}$ we should clear the purpose the college Students' training, not for some special Students' (such as Students' leaders, outstanding Students', etc.) but for the training activities of all the college Students', the purpose is not confined to the cultivation of outstanding leaders, but also focus on cultivating Students' extensive leadership, organization ability and interpersonal skills 。

\section{The Problems in the Cultivation of College Students' Leadership}

Through the teaching practice and the survey, we found that it is difficult to solve the problem of Students' understanding of leadership sensibility, unable to improve Students' practical leadership if we rely on the basic theoretical knowledge of learning, the transformation of knowledge to ability lack of practical and quantifiable ways, at the same time, we also lack of objective and comprehensive assessment of Students' leadership. At present, the research on the training and evaluation of Students' leadership is mainly having the following problems:

First, the concept of training is not advanced, innovative awareness is not enough. The development of College Students' leadership is limited to the study of theoretical knowledge and the practice of Students' cadres, and can not make the advanced education concept with its own characteristics to cultivate the innovation of the cultivation mode and method.

Second, the target model is not clear, targeted is not strong. In the current study, the concept and connotation of College Students' leadership are mostly from the leadership to the general concept of Lent, and it cannot reflect the Students' leadership characteristics.

Third, teaching and training system is not complete enough. At present, most of Students lack of leadership training system design, just stay on the theoretical training course, practice only by teachers and Students' cadres training in practice teaching activities. Teaching and training system, completeness and pertinence, training objectives vague, are not detailed, the mode of training, security needs, assessment and evaluation are not clear at all levels, there are no clear division of responsibilities, unreasonable allocation of resources, training incentive mechanism is weak. 
Fourth, the evaluation method is not accurate, operability is not strong. The effect of Students' leadership development needs to rely on the assessment to test. At present, the evaluation method is single, lack of the whole process, personalized evaluation mechanism, qualitative and quantitative, there are still lack of objective and comprehensive evaluation of the Students' leadership and potential.

\section{The Strategy of College Students' Leadership Training}

College Students' leadership training should enhance leadership as the theme, aims to cultivate Students' comprehensive quality and sound personality, promote the development of future occupation. At the same time, it is also the need of taking a forward-looking vision training future good leaders in the highly variable and diverse environment. ${ }^{[1]}$ The community should give attention, give full play to the society, the Students' themselves, and other various resources, co-ordinate the relationship between teaching and sports training, Students' daily leadership activities, through the orientation of training ideas, improving the training system, training process and the construction of evaluation system, promote college Students' leadership.

The Train of Thought of "General Knowledge". "Tsien Hsueshen's question" is a puzzle for our colleges and universities to cultivate outstanding talents. In recent years, more and more experts and scholars have realized that the university should pay more attention to general education, and leadership training is an important part of general education, leadership is the ability to anyone in need and can develop. The information society and the rhythm of the work intensity has put forward higher requirements for college Students', they must have ideals and beliefs, scientific culture, leadership and management skills, physical and psychological basis, not only has a strong development potential, and also have ability to meet social needs. For this purpose, in the training process we should clear that the leadership training should be included in general education, we need adopt a correct educational concept, rational allocation the teaching resources, train the Student's to meet the needs of society, not only proficient in the professional, but also familiar with the leadership, they all has a strong potential for the development.

Explore the Training System of Integration and Normalization. To achieve the goal of training, it is necessary to scientifically formulate and improve various mechanisms including curriculum, teaching methods, practical teaching, etc.. According to the needs of social development, we need optimize the Students' leadership model, establish the Students' leadership training and build evaluation index system, we need detail quantitative evalution criterion, decompose the training and evaluation target into the teaching, practice and life. On this basis, mobilize Students', administrators and teachers to achieve the training of integration and normalization.

Optimize the Whole Process of Training Process. The practice of leadership training is very strong. On the basis of theoretical study, it needs a lot of practice teaching. Foreign colleges and universities attach great importance to the cultivation of College Students' extracurricular activities, make full use of extracurricular practice link to train Students' leadership. We generally use the holiday to allow Students' to participate in social practice, there are some practical training effect, but it failed to effectively exercise the leadership of Students'. We need establish multi-level, all-round practice activities, create conditions for the whole process and allow Students' to carry out the practice of leadership activities, continuous accumulation of leadership experience. In the classroom teaching, we should carry out practical teaching activities; improve Students' extracurricular, simulation of the leadership mechanism, according to different situations, we need give Students' the corresponding authority, ensure the effective implementation of independent management of Students', guarantee every Students' has the opportunity to practice.

Construct the Evaluation System of "Refinement Management". it is an effective means to improve the leadership of college Students' through the evaluation of training effect, and is an objective measurement and evaluation of the effectiveness. For the evaluation of heavy knowledge and light ability, evaluation methods adhere to the comprehensive evaluation theory, we not only accept the theory exam evaluation, but also accept the assessment from the Students' and teachers. 
The evaluation process should be objective, committed to the investigation of the actual performance of Students', and timely record it in the form of report. We need to ensure the long-term evaluation, take the e evaluation activities throughout the Students' daily activities, most activities of Students' should be evaluated such as the Students' daily life and learning performance, build different evaluation information statements, collect those statements in order to assess objectively the Students' performance.

\section{References}

[1] CPC Central Committee. National outline for medium and long term education reform and development program (2010-2020), 2010 (7).p31

[2] John P. Dugan, Susan R. Theories. R. Komives In:Susan, etal.The Handbook Students' Leadership Development (First Edition).Printed the United States of America, 2010:1.p51

[3] Susan R. Komives. Advancing Leadership education.In Julie E. Owen. Assessment and Evaluation. In Susan R.Komives, etal.The Handbook for Students' Leadership Development (SecondEdition).Printed in the United States of America.2010:2.p32

[4] James M.Kouzes, Barry Z.Posner, The Challenge, Fourth Edition, John Wiley \& Sons, Inc, San Francisco, 2007.p45

[5] Li Jinlin, Wang Fangguan, Jin Haiyan. Students' leadership survey. Journal of Chongqing University of Technology (SOCIAL SCIENCE), 2010 t (11).p18

[6] Xi XinJie The strategic thinking of contemporary youth research ,Leadership Education Ef College Students' China 2012, (5).p34

[7] Zhu Deixin. The college Students' leadership. Consumer Research Herald, 2008, (9).p56

[8] Gao Jian. Study on leadership education of college Students'(MS.). Hebei University Of Science and Technology,China, 2012.p23

[9] Xu Guo Guo. Theoretical analysis of contemporary college Students' leadership model and its realization path. Journal of Beijing University of Posts and Telecommunications: Social Science Edition, 2011, (6).p41

[10] Huang Shanshan, the reform of the leadership education for college Students'. School Party Building and Ideological Education, 2016 (2),p33 